\title{
Chapter 8 \\ Blood Transfusion-Associated Infections in the Twenty-First Century: New Challenges
}

\subsection{History of Blood Transfusion}

Research into blood transfusion began in the seventeenth century after William Harvey experiments on the circulation of blood and Richard Lower pioneered the first blood transfusion between animals in 1665 [Royal Society]; but the first blood transfusion from animal to human was carried out by Jean-Baptiste Denys in France [Blood transfusion-Wikipedia]. The first successful blood transfusion was performed using a syringe by the British obstetrician James Blundell to treat postpartum hemorrhage in 1818. Subsequently, the first successful whole blood transfusion was performed to treat a patient with hemophilia in 1840 by Samuel Lane in London. Blood transfusions were avoided in the late nineteenth century because of severe reactions and high mortality.

It was not until 1901, after discovery of the three blood groups [O, A, and B] by the Austrian Karl Landsteiner, that blood transfusion became safer and led to the acceptance for modern treatment in emergency blood loss and surgeries [Wikipedia]. The first blood transfusion for surgery was performed in 1906 at Case Western Reserve University in Cleveland. The First World War was the stimulus for the rapid development of blood banks and transfusion techniques, and the world's first blood donor service was established in 1921 by the British Red Cross. The first blood bank was established in a Leningrad hospital in 1932 and the US government established a nationwide program for blood collection in 1940 [Highlights of transfusion medicine history; http://www.aabb.org/tm/Pages/highlights.aspx].

Transfusion was recognized as a source of infection before 1941 with description of transfusion-transmitted [TT] syphilis and screening for syphilis in blood donors was instituted before blood banks became common. In 1943, Paul Beeson published the classic description of TT-hepatitis [Highlights of transfusion medi- 
cine history], but the malarial parasite may be the first microbe known to be transmitted by transfusion. Globally, it is estimated that 85 million units of red blood cells are transfused every year.

\subsection{Adverse Effects}

Transfusions of blood products are associated with several complications and most of these are due to immunological reactions or infections. The immunological reactions are more frequent than infections and include (1) acute hemolytic anemia [most often due to human error in cross matching of mismatch blood types]; (2) delayed hemolytic reaction $>24 \mathrm{~h}$ to 28 days [usually due to low or undetectable anti-Rh and anti- Kid antibodies]; (3) febrile nonhemolytic reactions, one of the most common transfusion reaction that occurs in about $7 \%$ [due to release of inflammatory chemical mediators from stored white blood cells]; (4) allergic reactions caused by $\mathrm{IgE}$ anti-allergen antibodies from the donor or recipient [more common in patients with hay fever/allergies]; (5) rarely anaphylactic reactions, caused by IgA anti-plasma protein antibodies; (6) extremely rare posttransfusion purpura, associated with the presence of antibodies directed against both the donor and recipient platelets [human platelet antigen]; (7) transfusionassociated acute lung injury [similar to acute respiratory distress syndrome [ARDS]] within $6 \mathrm{~h}$ of transfusion, related to donor antibodies interacting with recipient tissue antigen with release of inflammatory cytokines resulting in capillary leakage; (8) and transfusion-associated graft versus host disease which occurs in immunodeficient patients whose body failed to eliminate the donor's $\mathrm{T}$ cells [Blood transfusion-Wikipedia]. A common non-immunological complication is transfusion-related circulatory overload within $6 \mathrm{~h}$ and acute respiratory distress with signs of heart failure.

\subsection{Infections Associated with Blood Products}

Blood products transfusion can cause infectious complications through three mechanisms: (a) transfusion of microbes present in asymptomatic donor blood [mainly viruses]; (b) contamination of stored blood products [primarily bacteria in platelets]; and (c) transfusion-related immunosuppression predisposing to postoperative infections and others. The risk of infection increases with the amount of red blood cell units or blood products transfused and patients requiring chronic blood or products are most vulnerable. 


\subsection{Transfusion-Transmitted Infectious Diseases}

Despite the remarkable progress made in blood or blood products safety achieved in the last 30 years since the identification of the human immunodeficiency virus [HIV] and hepatitis $\mathrm{C}$ virus [HCV], concerns still abound with the risk of transmission from emerging infectious agents. For microbes to be transmitted by transfusion certain attributes are considered necessary: presence of the agent in blood during the donor's asymptomatic phase, the agent's survival/persistence in blood during processing/storage, and the agent must be recognized as responsible for a clinically illness/outcome in a proportion of the infected recipients [1]. A group of experts in 2009 [members of the AABB's Transfusion Transmitted Diseases Committee] identified 68 infectious disease agents capable of being transmitted by blood transfusion [1]. However, the list now is even larger and will keep expanding as the rate of emergence of new agents from 1940 to 2004 was 3-5 new viruses discovered every year, 60-70\% from animal origin that can infect humans [2, 3]. The infectious agents were classified and prioritized on risk level based on combination of scientific/epidemiological assessment, public perception, and regulatory concern into red, orange, yellow, and white categories [1]. The list did not include the wellacknowledged transfusion-transmitted agents-HIV, HCV, hepatitis B virus [HBV], and Treponema pallidum.

Red agents have low to high scientific evidence of blood safety risk with the potential for severe clinical outcomes, including human variant of CreutzfeldtJakob disease [vCJD], dengue viruses [DENV], and Babseia species. vCJD has a low to very low risk of transmission in North America [NA] but higher risk of transmission in the United Kingdom [UK] where it was first described. DENV has a low to very low [almost absent] risk of transmission in NA but moderate risk in endemic countries. However, Babesia has moderate risk for transmission in the USA but very low risk in Canada and Europe or countries where the parasite is not endemic. Orange category agents have sufficient scientific/epidemiological evidence of blood transmission risk that may support higher priority in the future. These include Chikungunya virus [CHIKV], potential risk as not proven transfusion transmitted; St. Louis encephalitis virus [SLEV], potential risk but not proven; Leishmania species low risk with blood transmission proven in possibly 10 cases mainly in endemic areas [4]; Plasmodium species are well documented with blood transmission, low in non-endemic countries and high in hyperendemic regions; Trypanosoma cruzi [Chagas disease] is well documented to be blood transmitted, low in the USA and Europe but moderate in South and Central America. Yellow category agents have low to absent risk of blood transmission, but there is public and regulatory concern. These agents include chronic wasting disease [CWD] prion agent, never detected in humans or donated blood; human herpesvirus-8 [HHV-8], transmitted by transfusion in Africa [5] and possible in the USA but not proven [6], and resulted in no clinical disease; HIV variants are potentially blood transmissible but never proven; human parvovirus B19 which has been proven to be transmitted by blood [four documented cases by 2009], but very low risk except for hemophilia and conditions 
requiring recurrent chronic transfusion and immunosuppression; avian influenza $\mathrm{A}$ virus subtype H5N1 unlikely to be blood transmitted, but high profile for possible pandemic spread; simian foamy virus can be transmitted by blood transfusion in nonhuman primates, but never demonstrated in humans and is theoretically possible; Borrelia burgdorferi [Lyme disease agent] potentially possible but no proven cases of transfusion transmitted; and hepatitis A virus [HAV] is very rarely transmitted by transfusion in neonatal intensive care units. White category agents represent a watch list, subject to modifications with change according to circumstances. These agents include hepatitis E virus [HEV] which is documented to be blood transfusion transmitted in endemic regions and industrialized countries, mainly the zoonotic subtypes [7, 8]; and Anaplasma phagocytocytophilum which has been documented to be transfusion transmitted in the USA [ 8 cases by 2014] with potential for greater blood transmission due to high seroprevalence in some regions of the USA, unknown period of bacteremia, survival in refrigerated stored blood, and shown in animal models to be transfusion transmittable [1]. Since the AABB group publication in 2009, the list of agents was updated in 2014 with six new additions [9]. These included yellow fever viruses, miscellaneous arboviruses, XMRV, human parvoviruses other than B19, bocaviruses, measles virus, and MERS-CoV. Tables 8.1 and 8.2 lists the microorganisms recommended for screening donated blood.

\subsection{Recent Trends in Transmittable Agents in Blood Donors}

There is a strong correlation between the risk of transfusion-transmitted agents and the prevalence of endemic rate in the local population of the country or region. Hence epidemiological data on the prevalence of high-risk infectious microbes in blood donors can be used as a guide to assess blood transfusion risk in conjunction with other preventative measures. There is a marked regional variation in prevalence

Table 8.1 Screening for transfusion-transmissible infections

\begin{tabular}{|c|c|c|c|}
\hline \multicolumn{4}{|c|}{ Mandatory screening } \\
\hline Agent & Screening marker & Assay & Comments \\
\hline 1. HIV & $\begin{array}{l}\text { Anti-HIV, p24 Ag, } \\
\text { RNA }\end{array}$ & EIA, CLIA, NAT & $\begin{array}{l}\text { Ag-antibody assays for all some } \\
\text { countries NAT }\end{array}$ \\
\hline 2. $\mathrm{HBV}$ & $\begin{array}{l}\text { HBsAg, anti-HBc, } \\
\text { DNA }\end{array}$ & EIA, CLIA, NAT & $\begin{array}{l}\text { HBsAg—all, anti-HBc-few NAT- } \\
\text { some countries }\end{array}$ \\
\hline 3. $\mathrm{HCV}$ & $\begin{array}{l}\text { Anti-HCV, } \\
\text { HCV-Ag, RNA }\end{array}$ & EIA, CLIA, NAT & $\begin{array}{l}\text { Anti-HCV—all, ant-HCV/-Ag-limited; } \\
\text { NAT_-some areas }\end{array}$ \\
\hline $\begin{array}{l}\text { 4. } \\
\text { T. pallidum }\end{array}$ & $\begin{array}{l}\text { Anti-TP, } \\
\text { aniti-reagin }\end{array}$ & $\begin{array}{l}\text { TPHA, EIA, } \\
\text { VDRL/RPR }\end{array}$ & $\begin{array}{l}\text { EIA preferred; VDRL in high incidence } \\
\text { countries }\end{array}$ \\
\hline
\end{tabular}

Data obtained from the World Health Organization [WHO], Geneva; 2009. https://www.ncbi.nim. nih.gov/books/NKB142989/

$A g$ antigen, CLIA/EIA enzyme immunoassays, NAT nucleic acid technique, $H B c$ hepatitis B core 
Table 8.2 Selective screening for specific blood-transmissible infections

\begin{tabular}{l|l|l|l|l}
\hline Agents & $\begin{array}{l}\text { Screening } \\
\text { marker }\end{array}$ & Assay & Regions & Comments \\
\hline 1. CMV & Anti-CMV & EIA & None & Blood for immunosupp \\
\hline 2. Malaria & Parasite or Ag & $\begin{array}{l}\text { Thick smear, } \\
\text { EIA }\end{array}$ & Endemic, risk & Donor screening \\
\hline 3. . cruzi & Anti-T. cruzi & EIA & Endemic & $\begin{array}{l}\text { Migrants from endemic } \\
\text { areas—-screening }\end{array}$ \\
\hline $\begin{array}{l}\text { 4. HTLV I/ } \\
\text { II }\end{array}$ & Anti-HTLV-I/II & EIA & Endemic & Some non-endemic areas \\
\hline 5. WNV & $\begin{array}{l}\text { Anti-WNV, } \\
\text { RNA }\end{array}$ & EIA, NAT & $\begin{array}{l}\text { US, parts of } \\
\text { Europe }\end{array}$ & Seasonal \\
\hline 6. HEV & RNA & NAT & Parts of Europe & Controversial \\
\hline 7. B19V & DNA & NAT & $\begin{array}{l}\text { US, parts of } \\
\text { Europe }\end{array}$ & Pooled plasma prod. \\
\hline
\end{tabular}

Data obtained from [126]

$A g$ antigen, EIA enzyme immunoassay, NAT nucleic acid technique, immunosupp. immunosuppressed, prod. products

of these agents and the data in recent years will be presented by country, but is incomplete from lack of recent studies from some regions.

\subsubsection{China}

In China recent data from 2008 to 2015 for blood donors screened for HIV, HBV, $\mathrm{HCV}$, and syphilis from the southwest region showed a decreasing trend over the time period, from 2.39 to $1.98 \%$ [combination of the four agents], slightly lower than other regions [10]. Syphilis was the most prevalent, especially in females and farmers in rural regions. Since establishing the blood services, China had experienced several catastrophes with transfusion-transmitted diseases in the past, but since 1998 has undergone transformative changes in donor screening and donor testing. Donor selection is now voluntary donation with fixed groups and donated blood undergoes two rounds of testing with different equipment or reagents by different personnel [11]. Since 2010, nucleic acid test [NAT] was established in several blood centers and in 2015 the government invested for nationwide expansion of NAT. However, China's blood services do not screen for other agents, which are regionally endemic and can be transmitted by transfusion. A nationwide distribution of nine potential agents that could be targeted was recently reviewed. These infectious agents include Plasmodium spp., human parvovirus B19 [B19V], DENV, Brucella spp., severe fever with thrombocytopenia syndrome virus [SFTSV], Leishmania spp., HTLV, and Coxiella burnetii [Q fever] [12].

Despite malaria being endemic in some regions of China and previous reports of at least 87 cases transmitted by transfusion from 1992 to 2015 [12], the prevalence of malarial parasites in blood donors is unknown and screening of blood is not 
performed. DENV is also endemic in parts of China and blood donors in 2014 from endemic areas in Guangdong province had IgM prevalence rate of $2.4 \%$ with one donor with RNA load of 944 copies $/ \mathrm{mL}$. Brucellosis is endemic in the farming communities of North China and the prevalence rate among blood donors from an endemic area [Xinjiang Province] was reported in 2015 to be $1 \%$ and Brucella DNA was detected in $0.39 \%$ [13]. SFTSV, a tick-borne bunyavirus, was first described in China concentrated in the mountainous rural areas in central-eastern China with episodic outbreaks from spring to autumn. No transfusion-transmitted cases has been described and the seroprevalence rates in blood donors were $0.54 \%$ from endemic area and $0.28 \%$ from non-endemic area, and two low-grade suspected viremic samples were detected by RNA testing [12]. HEV is found worldwide and many cases have been transmitted by blood transfusion all over the world [14]. Screening of blood donors from six urban blood centers in China was reported in 2010 as showing prevalence of anti-HEV IgG of $32.6 \%$, anti-HEV IgM of $0.94 \%$, and HEV RNA in $0.07 \%$ among 44,816 donations [15]. HTLV prevalence in China is low and the latest nationwide surveillance in blood donors reported a rate of $0.03 \%$ in 2014 [16]. Leishmania spp. can be transmitted by transfusion and the parasite can survive in human red blood cells $[\mathrm{RBC}]$ in storage conditions up to 15 days [17]. Up to 2010, there were 300 cases of kala-azar reported yearly from China, mainly from Xinjiang Province and other western provinces [12]. However, there are no surveillance studies in blood donors and no documented transfusiontransmitted cases in China. B19V has been documented to be transmitted by blood transfusion and can cause RBC aplasia in the immunosuppressed [18]. Among Chinese blood donors, the B19V DNA was detected in $0.58 \%$ but was $4.8 \%$ in the Tibetan population. However, B19V DNA was detected in 54.2\% of plasma pools used to manufacture intravenous immunoglobulin, factor VIII, fibrinogen, etc. with viral loads of $1 \times 10^{2}$ to $1 \times 10^{7} \mathrm{gEq} / \mathrm{mL}$, which is higher than recommended by the US FDA $\left[1 \times 10^{4} \mathrm{gEq} / \mathrm{mL}\right]$ [12]. C. burnetii DNA has been detected in blood donated [0.3\%] of seropositive donors of $12.2 \%$ during a large outbreak of Q-fever in the Netherlands [19], but blood donor screening has not been initiated in China. Q-fever is mainly endemic in Tibet, inner Mongolia, and Western China.

\subsubsection{Africa}

The threat of blood-borne pathogens is disproportionately high in Sub-Saharan Africa, but there is variation among countries. In Eritrea, 60,236 blood donors were screened between 2010 and 2016, and at least $3.6 \%$ of donated blood was positive for one of the acknowledged transfusion-transmittable infections [TTI], HBV, HIV, $\mathrm{HCV}$ and syphilis, and $0.1 \%$ for multiple infections [20]. The seroprevalence of $\mathrm{HBV}, \mathrm{HCV}$, HIV, syphilis, and co-infections were $2.0,0.7,0.3$, and $0.6 \%$, respectively. These rates are relatively low compared to other countries in SubSaharan Africa. 
In Ethiopia, similar data was collected from 11,382 blood donors from 2008 to 2015 with overall seroprevalence of $6.6 \%$ of the TTI, and prevalence of HBV, HIV, $\mathrm{HCV}$, and syphilis were $4.4,0.6,0.8$, and $1.1 \%$, respectively [21]. Higher prevalence of any TTI was reported in Eastern Ethiopia [11.5\%] with the majority [94.5\%] due to HBV [22]. In Western Kenya, the seroprevalence of the four TTI in voluntary blood donors was even higher at 9.4\%, distributed among HIV, HBV, $\mathrm{HCV}$, and syphilis at $1.15,3.46,3.21$, and $1.56 \%$, respectively [23]. Prospectively screened donors from 2005 to 2016 in Nigeria showed 14. 96\% were infected with at least one of the four TTI with overall prevalence of HBV, HCV, Syphilis, and HIV of 4.1, 3.6, 3.1, and 4.2\%, respectively [24]. However, the rate of all TTI declined significantly over the years with a remarkable decline in HIV. The seroprevalence of the four main TTI among blood donors reported from 17 different and reported between 2009 and 2016 was recently reviewed [25]. This study found that West African countries had the highest seroprevalence of the TTI than other countries, especially for HBV [10.0-14.96\%] and HCV [1.5-8.69\%], but HIV prevalence demonstrated declining pattern throughout the years. Blood transfusion-transmittedassociated HIV infection in Nigeria was previously reported to be responsible for 14 [2.3\%] of 597 children infection between 2004 and 2011 [26]. The Western Cape Province of South Africa's blood supply appears to be exceptionally safe with the introduction of NAT since 2005 [27].

\subsubsection{Middle East}

The prevalence rate of the main TTI in blood donors appears to be lower in Middle Eastern countries than in Africa and Asian countries, with declining rates from 2004 to 2014 in Iran [28]. The overall seroprevalence rates of HBV, HCV, and HIV were $0.15,0.1$, and $0.004 \%$, respectively. Similarly, low rates of TTI have been reported among blood donors from Jordan [29]. Data from Egypt in 2013 indicate that the prevalence of HIV and syphilis were extremely low [0\%] but HCV and HBV were $7.2 \%$ and $2.3 \%$, respectively, still posed a significant risk of blood transmission [30]. Recent prevalence data from Saudi Arabia among blood donors used serological testing and NAT from relatively small sample [3028] found: HBV sAg $0.33 \%$, HCV $0.40 \%$, HIV $0.13 \%$, HTLV $0.20 \%$, and HBV cAbs $9.81 \%$; with additional detection by NAT.

\subsubsection{Southeast Asia}

Among blood donors from Pakistan [2014-2015] TTI was detected in 5.46\% and $0.38 \%$ had multiple infections by rapid immunochromatographic technique [31]. The overall frequency of HCV, syphilis, HBV, malaria, and HIV was 2.62, 1.55, $1.10,0.10$, and 0.02 , respectively. The prevalence rate of the TTI appears to be lower 
in India with overall positive for any TTI among the donors $2.79 \%$ in Kolkata [32] and the cumulative seroprevalence in Darjeeling of HIV, HBV, HCV, and syphilis of $0.42,1.24,0.62$, and $0.65 \%$, respectively [33]. Another study from India reported that the prevalence of TTI was higher in replacement donors than voluntary donors, but overall decreased from 2008 to 2012 [34]. The prevalence of infection in donated blood has been decreasing in Thailand from 2010 to 2012 compared to 2007-2009, and rates up to 2012 for HIV, HBV, HCV, and syphilis were 0.26-0.28, 0.97-1.42, $0.26-0.42$, and $0.35-0.53 \%$, respectively [35].

\subsubsection{South America}

Seroprevalence data of the usual TTI in blood donors in South American countries are incomplete and only partially present for few countries within the last 5 years. In Brazil, NAT was introduced for HIV and HCV in 2012 and the prevalence of these two viruses was recently estimated to be 209.9 and 66.3 per 100,000 donations, respectively [36]. Argentina introduced NAT screening in blood banks for $>10$ years and reported positive donors for HIV at $0.075 \%$, HCV $0.05 \%$, and HBV $0.045 \%$ [37], which may represent intermediate risk in comparison between African countries and developed nations. Limited data from Colombia of 41,575 donors over a year note prevalence rates of: Chagas disease $0.49 \%$, HBV $0.21 \%$, HCV $0.45 \%$, HIV $0.12 \%$, and syphilis $1.68 \%$, total prevalence of $2.95 \%$ [38].

\subsubsection{Developed Countries}

Most high-income industrialized countries have very low rates of the usual TTI in blood donors but recent updates of seroprevalence are only present for a few. Data from 14.8 million donations were collected from 2011 to 2012 in the USA, representing $50 \%$ of the blood supply [39]. Surveillance-positive rates per 10,000 donations were: HBV, 0.76 [0.00076\%]; HCV, 2.0 [0.002\%]; HIV, 0.28 [0.00028\%]; and HTLV 0.34 [0.00034\%]. The Dutch experience from 1995 to 2014 was recently updated and the prevalence of TTIs among blood donors was 6 to 60 -fold lower than the general population [40]. New donors had higher rates of TTIs compared to repeat donors, and the prevalence rates of the TTIs from 2009 to 2014 per 100,000 donors were: HBV, 39 [0.00039\%]; HCV, 16 [0.00016\%], HIV, 2.4 [0.00024\%], HTLV, 4.2 [0.00042\%], and syphilis, 28 [0.00028\%]. The prevalence of TTIs in the Dutch donor population was typically lower than in other industrialized countries where the rates varied from 32 to 136 for HBV, 31 to 82 for HCV, 1 to 4 for HIV and 1 to 10 for HTLV per 100,000 donors [40]. 


\subsection{Risk of Transfusion-Transmitted Infections}

The risk of TTIs is variable in different regions of the world and is dependent on several factors: prevalence of TTIs in the donor population, type of donors routinely used [voluntary, replacement, or paid], screening or deferral of donors, method of testing blood donated [serology, antigen detection, and NAT], and pathogen reduction techniques for treating donated blood. In general, industrialized countries use multiple methods, including NAT, plus with a low prevalence of the major TTIs have the lowest risk of TTIs. Poor or low-income countries, especially in Africa, with a higher prevalence of TTIs, less dependent on voluntary donation and lacking facilities for NAT have the greatest risk of TTIs. Whereas, middle-income countries [Brazil, China, etc.] have intermediate risks of the usual TTIs, see Table 8.3 for comparative rates of TTIs [41-44].

\subsection{Risk of Blood Transmission of Specific Viruses}

\subsubsection{Cytomegalovirus}

Cytomegalovirus [CMV] latent infection is very common in the adult population of industrialized countries [about 60\%] and developing nations [ $>80 \%$ ] and can be transmitted by blood, as it resides in leukocytes, once a person is infected indefinitely. Transmission of CMV does not pose a significant health hazard to the healthy adult or older child, but it can result in severe disease in the immunocompromised CMV-seronegative patients, i.e., stem cell transplantation and for premature neonates. Measures to reduce TT-CMV for high-risk groups include depletion of cellular blood products [leukoreduction] and selection of CMV-negative donations. Studies indicate that newly positive CMV-IgG donors pose the highest risk of transmitting CMV as their blood contains the highest levels of CMV DNA [45]. However, there is no scientific evidence according to a recent review that leukoreduction or any single strategy reduces the risk of TT-CMV infection in high-risk patients [46].

Table 8.3 Residual risk of TTI in various regions of the world

\begin{tabular}{l|l|l|l|l}
\hline Agents & High income & Middle income & Low income & Comments \\
\hline 1. HIV & $\leq 0.33 \times 10^{-6}$ & $\leq 11 \times 10^{-6}$ & $\leq 64 \times 10^{-6}$ & Depends on NAT \\
\hline 2. HBV & $\geq 0.16 \times 10^{-5}$ & $\geq 289 \times 10^{-5}$ & $\geq 534 \times 10^{-6}$ & Depends on NAT \\
& $\geq 0.16 \times 10^{-6}$ & & & \\
\hline 3. HCV & $\geq 0.03 \times 10^{-6}$ & $\geq 191 \times 10^{-5}$ & $\geq 207 \times 10^{-6}$ & Depends on NAT \\
\hline
\end{tabular}

Data obtained from [43, 127, 128]

NAT nucleic acid technique

Note: High-income countries as exemplified by France; middle-income countries as exemplified by Brazil; low-income countries as in Sub-Saharan Africa, i.e., Gabon 


\subsubsection{Occult Hepatitis B}

Transfusion-transmission of HBV is extremely low in developed and middleincome countries that screen blood for HBsAg and NAT, but a residual risk still remains from blood donors with extremely low viral DNA in the blood with occult HBV infection, that are intermittently shed from the liver or not detectable by even highly sensitive NAT. Models estimate a residual transmission risk of 3-14\% with occult HBV donation after HBsAg and NAT non-reactivity [47]. Despite NAT testing for HBV, up to 2013 4-13 cases of TT-HBV infection occurred annually from occult or recent infection in the window period in Japan [48]. Individual NAT revealed that $1.94 \%$ of donations with low anti-HBc and anti-HBs titers were viremic. Since then the Japanese blood services had elected to discard all units with low anti-HBc and anti-HBs that accounted for only $1.3 \%$ of total donations [48]. A study from Australia [without universal anti-HBc testing] estimated that occult HBV residual risk was 1 in 982,000 units transfused which represented 55\% of the total HBV risk, and was decreasing with individual NAT identifying repeat blood donors with occult infection [49]. Data from Brazil indicate that the presence of high antiHBs titers [ $>100 \mathrm{mIU} / \mathrm{mL}]$ did preclude the presence of HBV DNA in the donor blood [50].

A recent study reported that 3 Slovenian blood donors with occult HBV infection infected 9 of 31 [29\%] recipients with extremely low viral loads [51]. The study suggested that the minimal infectious dose should be revised from 100 to 16 copies [or 3 IU] of HBV DNA and that further prevention could be achieved by universal anti-HBc screening [performed by a few centers] or highly sensitive NAT able to detect 0.8 copies $[0.15 \mathrm{IU} / \mathrm{mL}]$ or pathogen reduction methods.

\subsubsection{Hepatitis $E$}

Hepatitis E virus [HEV] is of worldwide distribution with $>20$ million cases each year in tropical/subtropical countries causing more than 56,000 deaths each year [52]. Endemic and epidemic diseases in these countries [Asia, Africa, Central America, etc.] are caused by genotypes 1 and 2 by oral-fecal route of transmission. But in Europe, North America, and parts of Asia [i.e., Japan] genotypes 3 and 4 are zoonoses present in many animals [especially domestic pigs] that cause sporadic infections by consumption of raw or undercooked pork but also by blood transfusion [53]. HEV viremic blood donors are usually asymptomatic with normal transaminase and donor screening interviews are not beneficial. Moreover, the asymptomatic HEV-viremia can be present for up to 68 days [54]. Although most infection with HEV causes asymptomatic or mild hepatitis, fulminant disease is seen in pregnancy and patients with preexisting cirrhosis and chronic hepatitis progressing to cirrhosis can occur in the immunosuppressed [53]. This is also of concern as organ transplant recipients and patients with hematological malignancy 
more commonly receive blood or blood products transfusion, and immunocompromised patients develop chronic HEV in about $60 \%$ with infection [55].

HEV [genotype 1] transmission by blood transfusion was first described in an endemic area in 2004 [56], but since then most cases have been reported in industrialized countries with genotype 3. Cases have been reported from Europe [France, Germany, Spain, the UK], Australia, Canada, and Japan [57]. TT-HEV can occur with transfusion of RBCs, platelet concentrate, fresh frozen plasma, and pooled granulocytes. Presently, there are about 40 cases of TT-HEV with 21 from Japan and at least 17 cases of transfusion of HEV blood products not resulting in HEV infection [57]. Universal screening of blood products for HEV RNA is a very controversial topic in Europe and policies vary among countries. In 2012-2013 in England, 225,000 blood donations were retrospectively screened and 79 had detectable HEV RNA [1:2850], and follow up of 43 recipients showed 18 [43\%] had evidence of HEV infection [58]. The prevalence of HEV viremia in blood donors vary from 1:762 in the Netherlands to 1:9500 in the USA, and the risk of viremic blood leading to infection was estimated to be 40-50\% [59]. The risk of developing clinical infection in the recipient of viremic blood products may depend on the presence of antibodies, viral load, and volume of transfused blood. The minimal infective dose is unknown but low viral load $<100 \mathrm{IU} / \mathrm{mL}$ has not been associated with $\mathrm{HEV}$ infection and the lowest inoculum known to lead to infection in the recipient is $2 \times 10^{4} \mathrm{IU}$ [58]. HEV RNA screening of blood donations is now routinely performed in Ireland, the UK, and the Netherlands, but selective screening for use in high-risk patients is performed in some blood centers in Germany, France, and Switzerland [57].

\subsubsection{Arboviruses}

Arboviruses are of worldwide distribution with regional variation depending on the species. There is a significant risk of transmission by transfusion during the short period of asymptomatic viremia, especially during peak season with a high incidence of infection. However, it is often difficult to prove TT-arbovirus infection from vector-borne transmission in endemic regions. Although transmission by blood products had been proven only for a few arboviruses, there is a major concern since the Zika virus epidemic in the Americas 2 years ago. Infection with Zika virus is the most commonly asymptomatic and viremic donors could be easily missed. Moreover, TT-Zika to pregnant women could result in severe neurological fetal abnormalities [60].

Although Colorado tick fever virus was the first arbovirus reported to be transmitted by blood transfusion in 1975 [61], concerns of TT-arboviruses became a blood safety issue, not until the West Nile virus outbreak in the USA in 2002. West Nile virus causes asymptomatic infection in the majority of patients [about 80\%], but the severe neurological disease can occur in the elderly and immunocompromised subjects. In the US outbreak, 16 blood donors were linked to 23 infected 
recipients and all donors were negative for West Nile-specific IgM antibody at the time of donation [62]. The estimated risk of TT-West Nile virus during the epidemic period was $1.46-12.33$ per 10,000 donations [63]. Since then yearly seasonal outbreaks [summer to fall] have occurred in North America but with decreased intensity. National screening by NAT was instituted in 2003, initially by minipool but after 2 years switched to individual donation, as one-third of RNA-positive donations were missed by minipool screening due to low-level viremia which can cause infection [64]. The estimated cost-benefit of West Nile virus screening in the USA in 2003 was $\$ 483,000$ per quality-adjusted life year [65].

Other arboviruses shown to be transmitted by transfusion are dengue virus [DENV] and tick-borne encephalitis virus [66]. Despite high incidence of dengue fever in many tropical countries, annually at least 50 million globally, DENV has rarely been reported to be transmitted by transfusion. Up to 2016, there were only 5 well-documented clusters of TT-DENV infection [67]. However, a retrospective analysis of a large 2012 epidemic in Brazil was able to identify the 6th cluster of TT-DENV [68]. DENV-4 viremia was confirmed in $0.5-0.8 \%$ of donations during the epidemic and 42 DENV RNA-positive units were transfused to 35 recipients. However, 6 infections occurred in 16 susceptible recipients [37.5\%]. Analysis revealed no significant association with transmission and viral load and $90 \%$ of donors and recipients had evidence of past DENV infection of one or more serotypes.

Chikungunya virus [CHIKV] is another arbovirus that results in clinical illness mimicking dengue fever, but results in more severe and persistent arthralgia and arthritis, and is widely distributed in the tropics with large outbreaks in the Americas and Caribbean in 2013-2014 [60]. CHIKV potentially can be transmitted by transfusion but there is no report of this occurring. CHIKV infection differs from DENV, Zika virus, and West Nile virus infections as most infected subjects are symptomatic and, thus, there is a lower risk of asymptomatic viremic donations. The risk of TT-CHIKV was recently assessed in a study from Thailand. The mean and maximal risks of viremic donations during an epidemic period was estimated to be $0.9 \%$ and $4.8 \%$, but with only $10 \%$ asymptomatic cases, screening of donors could reduce the risk by $88.4 \%$ [69].

The rapid pandemic spread of Zika virus [ZIKV] since 2015 with reported cases in 85 countries and territories has posed the greatest risk for TT-arbovirus. Most viremic patients infected with ZIKV are asymptomatic and pose a threat to the blood supply in outbreaks and low endemic spread. Moreover, ZIKV produces severe teratogenic effects, can persist in whole blood up to 2 months [70] and four possible cases of TT-ZIKV have been reported from Brazil [71, 72]. During the ZIKV outbreak in the French Polynesia of 2013-2014, 42 of 1505 blood donors [2.8\%] were positive for ZIKV RNA and only 11 subsequently became symptomatic [73]. Puerto Rico introduced NAT of donated blood in 2016 during an outbreak and ZIKV RNA was detected in up to $1.1 \%$ [74]. Similarly, NAT of asymptomatic blood donors in Martinique in 2016 detected ZIKV RNA in $1.8 \%$ and 54\% reported symptoms 1-6 days post-donation [75]. In the mainland USA, more than 200 locally acquired cases of mosquito-borne ZIKV infection and >5300 cases of travelassociated infection have been reported [76]. As a consequence since August 2016, 
all donated blood in the USA has been screened for ZIKV RNA. Over four million donations were screened with 9 confirmed positive [only on individual tested samples] for a rate of 1:480,654 donations [77]. ZIKV RNA levels in RBC varied from 40 to 800,000 copies/mL and detection up to 154 days after donation, but in plasma detected levels ranged from 12 to 20,000 copies $/ \mathrm{mL}$ and detection up to 80 days after donation. The present plan of NAT of individual donors is projected to cost $\$ 137$ million annually [78] and the cost-effectiveness of the blood donation screening exceed \$1 million/quality-adjusted life-year [QALY] gained, which is about 10 times as high as costs considered appropriate in clinical medicine [79]. The current US strategy for individual NAT for ZIKV was more recently estimated to cost \$341 million per QALY and screening was cost-effective only in the high mosquito season in Puerto Rico [80].

Ross River virus [RRV] is an arbovirus unique to the Australian region with confirmed cases of 5000 per year with the largest outbreak affecting 50,000 people in Australia, Papua New Guinea, and the Solomon Island and with recognized risk to the blood supply [81]. Like CHKV, RRV can cause epidemics of debilitating polyarthritis. The first case of TT-RRV was recently described, which prompted a comprehensive risk review. Modeling estimated the risk of infection in donors in Australia as 1:14,943 to 1: 95,039 and predicted 8-11 RRV-infected blood components issued in Australia during a 1-year period [82].

\subsubsection{Other Viruses}

Parvovirus B19 [B19V] infection is common in childhood and adulthood with seroprevalence of $30-40 \%$ in adolescents and $40-60 \%$ in adults, and more than $85 \%$ in the elderly population [83]. Many infected subjects are asymptomatic [approximately $25 \%$ of adults and $50 \%$ of children in outbreaks] or experience mild nonspecific viral-like illness [84]. Thus, blood may be donated during the period of viremia which occurs 1 week after exposure and lasts for about 5 days. An important pathogenic feature of B $19 \mathrm{~V}$ is the bone marrow cell tropism, especially erythroid progenitor cells, with increased susceptibility for infection with differentiation [85]. Transmission of B19V through blood products is feasible as high-level viremia regularly occurs during primary infection with $>10^{12} \mathrm{geq} / \mathrm{mL}$ in the early phase of acute infection of asymptomatic individuals [86]. B19V is frequently found in blood and plasma donations and is more commonly transmitted by pool plasma-derived products than $\mathrm{RBC}$. Transmission via plasma-derived products can occur due to incomplete clearance of the virus from the blood, high-level viremia in acute infection, and the resistance of the B19V to most inactivation procedures used in preparing blood-derived products [87].

$\mathrm{B} 19 \mathrm{~V}$ is a frequent contaminant of blood and plasma donations and the virus DNA is most commonly found in blood products from multiple donors. B19V DNA is detectable in $50-80 \%$ of non-inactivated factor VIII concentrates and in 30-50\% of solvent/detergent-inactivated IX concentrates [88]. High rates of B19V DNA 
have been found in albumin [25\%], immunoglobulin [IgG] preparations [20-75\%], factor IX, and pooled plasma [>60\%] with viral loads of $1 \times 10^{2}$ to $1 \times 10^{8} \mathrm{geq} / \mathrm{mL}$ [87]. Since no B $19 \mathrm{~V}$ transmission has not been documented from pooled-plasma products with less than $10^{3}$ to $10^{4} \mathrm{IU} / \mathrm{mL}$ B19V DNA, the US Food and Drug Administration [FDA] imposed a limit of $10^{4} \mathrm{geq} / \mathrm{mL}$ B19V DNA from pooled plasma [87]. Cellular blood products are found to have B19V DNA in about $1 \%$ and $\mathrm{RBC}$ transfusion has been associated with the transmission of B19V primarily with high-level titers of $>10^{7} \mathrm{IU} / \mathrm{mL}$ [89]. However, a recent report from Japan described persistent symptomatic B19V infection with severe thrombocytopenia transmitted by RBC transfusion low levels of B19V DNA $\left[1.0 \times 10^{4} \mathrm{IU} / \mathrm{mL}\right]$ [90]. Fortunately, most patients with TT-B19V are asymptomatic but the extent of clinical disease from transfusion transmission is unknown. The development of disease is influenced by the presence of hematological and immunocompromised disorders and the immune status of the host. Three groups of patients are at particular risk for serious disease with infection. Patients with chronic hemolytic disorders [i.e., thalassemia major, sickle cell disease] may develop transient aplastic crisis with acute infection; subjects with combined immunodeficiency syndrome can develop chronic severe anemia from bone marrow failure; patients with AIDS can develop pure red cell aplasia; and fetal abnormalities [hydrops fetalis] can occur in pregnant women [87]. Methods used to ensure safety of plasma-derived products include NAT of plasma minipools and individual donations and multiple steps of viral inactivation and removal with solvent/detergent, superheating at $80^{\circ} \mathrm{C}$ for 3 days, pasteurization, and nano-filtration [87].

Human T-lymphocytic virus types-1 and -2 [HTLV-1 and -2] are retroviruses that chronically infect lymphocytes that can be transmitted by transfusions, but only a small proportion of infected individuals will develop clinical diseases after many years. HTLV-1 infects five to ten million people worldwide from Africa, Asia, Caribbean, Central and South America and can cause debilitating spastic myelopathy, HTLV-associated myelopathy [HAM], and adult T-cell leukemia/lymphoma [ATL] [91]. HTLV-2 has not been linked with any specific disease entity but there is limited evidence that some affected patients may develop chronic neurological problems [sensory neuropathies, gait disturbance, bladder dysfunction, motor abnormalities, and mild cognitive impairment] and chronic lung infections and dermatitis [92]. HTLV-2 primarily occurs in the Americas, especially in Amerindians in North, Central, and South Americas [5-30\% seropositivity] and in pygmy tribes of Africa; but the virus has been found in intravenous drug abusers [IVDA] in the USA and southern Europe [10-15\%] [93]. Both HTLV-1 and -2 [primarily HTLV-1] have been shown to be transmitted by cellular blood products in Asia [first reported in Japan], Caribbean [Jamaica], and North America, but rarely recognized clinically [93]. A heart transplant recipient in France was reported to develop early signs of HAM within 4-5 months of TT-HTLV-1, the rapid onset most likely related to immunosuppression [94]. Two cases have been reported of ATL after TT-HTLV-1 in Taiwan in patients with pre-existing lymphoma and promyelocytic leukemia, 6 months and 11 years after the transmission [95]. Currently, many countries test for HTLV-1/2 antibodies in blood donors which may be cost-effective in high prevalence 
regions, but its value in high-income low-prevalence countries that perform universal screening is controversial and debatable [93]. Using a mathematical costeffective model, it has been estimated that testing all new blood donors for HTLV costs US $\$ 9.2$ million per life saved, or $\$ 420,000$ per quality-adjusted life-year gained, when the HTLV prevalence is 1 per 100,000 [96]. When the prevalence among donors is 10 per 100,000 the cost is estimated to be US $\$ 0.9$ million per life saved, or $\$ 41,000$ per quality-adjusted life-year gained. In many developed countries in North America, Europe, and Australia where the prevalence of HTLV-1 is less than 1 per million universal testing of donors does not appear to be costeffective; yet in many low- and middle-income countries with much higher prevalence antibody screening is not performed [93]. Further investigation of filter leukoreduction and pathogen inactivation methods and their cost-benefit compared to antibody screening are needed to guide national blood collection systems.

\subsection{Transfusion Transmission of Parasites}

\subsubsection{Malaria}

The malarial protozoa, Plasmodium species, appear to be one of the first, if not the first, TT-infection described in 1911 [97]. The major four Plasmodium species [P. falciparum, $P$. vivax, P. malariae, and P. ovale] can cause TT-malaria, as they can survive in stored blood even when frozen [98]. The longest interval between exposure and transmission by donation was estimated to be variable by species: 8 years for $P$. falciparum, 5 years for $P$. vivax, 7 years for $P$. ovale, and 44 years for $P$. malariae [97, 98]. TT-malaria has been described in both endemic and non-endemic countries. The risk of TT-malaria is extremely rare in industrialized countries but still a major challenge in resource-limited endemic countries, especially in subSaharan Africa. In endemic countries, it is challenging to differentiate between mosquito-transmitted from TT-malaria and, thus, transmission by blood transfusion is frequently unrecognized and underestimated. Recent estimates indicate that TT-malaria is $<0.2$ cases per million in non-endemic countries to $>50$ cases per million in endemic countries [98]. Donors are asymptomatic and invariably semiimmune with low levels of parasitemia that can be missed on microscopy. Transmission is usually through whole blood or packed RBC but platelets and leukocytes seldom transmit malaria from RBC carry over.

Recent studies within the past 10 years demonstrated a high-risk TT-malaria in sub-Saharan countries with median prevalence of malaria parasites in donated blood by thick smears of $10.2 \%$ [range $0.7 \%$ in Kenya to $55 \%$ in Nigeria] [99]. Blood donors are not routinely tested for malaria in most malaria-endemic countries in Africa including Nigeria. In Pakistan, blood smear detected malarial parasites in $0.57 \%$ of healthy blood donors and in India the rate was $0.03 \%$ with rapid diagnostic tests confirmed with microscopy $[100,101]$. Although non-endemic regions are 
at very low risk for TT-malaria, this may depend on the proximity to endemic areas. In Brazil, malaria is endemic in the Amazon River basin and non-endemic in the extra-Amazon regions, i.e., Sao Paulo state. However, a recent study found that $7.4 \%$ of blood donors from Sao Paulo were positive for P. falciparum [5.14\%] or P. vivax [2.26\%] [102].

A recent review of TT-malaria in non-endemic regions reported 100 cases from 1911 to 2015 with only a few cases in the twenty-first century, the two most recent cases in 2015 were from the USA [103]. Fifty-four of these cases occurred in the American continent, 38 in Europe, 3 in the Mediterranean area, 1 in India, and 4 in Southeast Asia. The frequency of the different Plasmodium species was: $P$. falciparum $45 \%$, P. malariae 30\%, P. vivax 16\%, P. ovale 4\%, P. knowlesi 2\%, 1 mixed infection with $P$. falciparum/P. malariae, and 1 case of an avian species [Plasmodium praecox] acquired in Greece. Fatal outcomes occurred mainly with $P$. falciparum [11/45] and rarely from $P$. malariae [2/30] or P. ovale [1/4] but the fatalities were not attributable to malaria [103].

Preventative measures taken by blood banks to avoid TT-malaria varies widely even in endemic regions and only a few countries in sub-Saharan Africa [Malawi, Sao Tome, Principe, and Sierra Leone] screen donated blood for malaria as of 2010 [98]. In non-endemic countries also varies with some countries [i.e., USA] rely on predonation questionnaire for potential screening and others [France, UK, and Australia] use antibody testing on donors considered at risk from preliminary questionnaire [103]. Screening of donated blood is most commonly by microscopy of blood smear or rapid diagnostic tests which are insensitive for low parasitemia, and serological tests cannot differentiate between remote and current infection. PCR is the most sensitive method but most endemic resource countries cannot afford this method for widespread use. Pathogen inactivation method using a combination of riboflavin as a photosensitizer with UV light device [Mirasol System for Whole Blood, Terumo BCT, Lakewood, Colorado] can reduces TT-malaria without damaging RBC [104].

\subsubsection{Chagas Disease}

Trypanosoma cruzi, the cause of Chagas disease, is widespread throughout rural Central and South America where it is transmitted by the triatomine bugs among the poor living in substandard houses. Severe cardiac disease occurs in 30-40\% of chronically infected untreated individuals. TT-Chagas disease [CD] has been recognized in endemic areas for many years where screening of blood donors has been instituted [105]. With increased migration of Latin Americans to North America and Europe, TT-CD in non-endemic countries has become a concern. Transmission of CD was first recognized to be transmitted by transfusion in 1952 and the total number of TT-CD is estimated to be 300-800 in the last decades [106]. TT-CD in non- 
endemic countries has been reported from the USA [ $n=7]$, Spain $[n=5]$, Canada [ $n=2$ ], and Australia [106] and recently Switzerland [107].

Low-level parasitemia may be detected several years after infection in asymptomatic individuals in up to $50 \%$ of those infected and the parasite can survive blood storage at $4-22{ }^{\circ} \mathrm{C}$ and even freezing and thawing [106]. Cellular components of blood can transmit the disease but not plasma. Platelet transfusion is the most commonly reported blood products associated with TT-CD probably because of the higher parasitic load than other blood products [108]. Prevention of TT-Chagas includes universal or selective donor screening [questionnaire] and testing for T. cruzi antibodies. Blood donor screening in the USA was first instituted in 2007 for Chagas disease and as of December 2017, at least 2300 infected blood donors were reported from blood banks in the USA [CDC. Chagas disease surveillance activities—-seven states, 2017. Weekly/July 6, 2018/67[26]:738-41]. Donor screening for Chagas disease in non-endemic countries includes: USA, Canada, Spain, UK, France, Switzerland, and Australia [106].

\subsubsection{Babesiosis}

Babesiosis is a zoonosis caused by an intraerythrocytic parasite, Babesia spp., most commonly Babesia microti, usually transmitted by Ixodes ticks and resembles the malarial parasite on the blood smear, but smaller. Babesiosis is most commonly reported from the Northeast and upper Midwestern USA, Europe and Asia Pacific including China. In immunocompetent hosts, it causes mild febrile illness, but severe disease with significant mortality occurs in immunocompromised, asplenic, and elderly patients. TT-babesiosis was first described in 1979 in the USA and since then there have been over 200 cases related to transfusion described with mortality of about 18-19\% [109-111]. Over 95\% of the cases were due to B. microti but at least 3 cases were from Babesia duncani [109] and recently a case from Arkansas secondary to Babesia divergens from multiple RBC transfusion was described [112]. Babesiosis has been transmitted by RBC stored for up to 35 days and by previous frozen RBC and rarely by platelets [113].

TT-babesiosis in endemic regions of the USA is increasing and of a public health concern as screening donors for $B$. microti is not yet mandated or routinely performed. Babesia seroprevalence in blood donors in foci of New York has been found to be up to $4.3 \%$ and $3.0 \%$ along the coastal Connecticut [111]. In a study on screening donated blood from Connecticut, Massachusetts, Minnesota, and Wisconsin with serology and PCR for B. microti, 335 [0.38\%] of 89,153 blood samples were confirmed positive with 67 [20\%] PCR-positive [114]. Thus, screening of donated blood in endemic regions of the USA would decrease the risk of TT-babesiosis. 


\subsection{Bacterial Infection from Blood Transfusion}

Bacterial infections represent the foremost infectious risk from transfusion of blood products. This is most commonly due to bacterial contamination during the processing or storage of blood products [direct effect], but there is increasing recognition of an indirect effect. Blood transfusion is associated with immunomodulation which may result in increased risk of infection. Leukocyte reduction of blood has been shown to reduce the risk of health care-associated infections [115]. In a recent review of health care-associated infection after RBC transfusion, restrictive transfusion compared to liberal transfusion strategy did not reduce the overall health careassociated infections, but reduced the risk of serious infections [116]. This was particularly significant for patients undergoing hip and knee arthroplasty as well for those with sepsis.

Bacterial contamination of blood products can be from the donor's skin [i.e., Propionibacterium acnes or staphylococci] or from the environment with a variety of bacteria: Yersinia, Pseudomonas, Proteus, Escherichia coli, Klebsiella, Acinetobacter, and Serratia [117]. Some investigations found Yersinia enterocolitica as being most common as the organism is capable of growing and multiplying at low temperatures. Septic transfusion reaction is most commonly from platelet rather than RBC transfusion. Estimated risk of blood products contamination with bacteria is 1 in 5000 for platelets and 1 in 30,000 for RBC [117]. There is recent evidence from the Netherlands that platelet concentrate stored in platelet additive solution is associated with fourfold increased risk of bacterial infections [118]. In the USA, approximately 2.2 million units of platelets are transfused yearly [2011 data] and over a 5-year period from 2009 to 2013, 13 fatalities from bacterial contamination of platelet products were recorded, 2.6 per year or $\approx 1.3$ per million platelet transfusion [119]. Since then there does not appear to be any improvement, as 5 fatalities were recorded from a bacterial infection in 2015 [120]. Staphylococcus aureus accounted for the greatest number of deaths due to contamination in the preceding 5 years [5/18] and other bacteria associated with fatalities included: Serratia marcescens, Klebsiella pneumoniae, Morganella morganii, Pseudomonas fluorescens, Acinetobacter species, and Enterococcus faecium.

Studies on active and passive surveillance for bacterial contamination of platelets have been reported with the culture of platelet samples. In a study over a 7-year period [2007-2013], 20 of 51,440 platelet units transfused were bacterially contaminated $[0.004 \% ; 389$ per million] and only resulted in 5 septic transfusion reaction [121]. In high-income countries bacterial contamination of platelets, though the most common transfusion-transmitted infections, ranging from 0.01 to $0.07 \%$ of platelet units, but the rates are much higher in resource-poor countries such as in Africa. The rate of bacterial contamination in whole blood or RBC concentrate in 7 studies from sub-Sahara Africa average $8.8 \%$ and platelet contamination is likely much higher [122]. To prevent bacterial contamination of platelets the US FDA 
recommends enhanced bacterial testing or pathogen reduction/inactivation strategies or both. One system which combines ultraviolet A and amotosalen for broadspectrum pathogen inactivation is approved in the USA and Europe [123].

\subsection{Summary and Future Directions}

Although the blood supply is safer than ever before, there are still major concerns with respect to transfusion-transmitted infections, especially with the advent of emerging infectious agents. Moreover, the situation in resource-poor countries, especially in sub-Saharan Africa, still remains a challenge to provide safe blood supply comparable to developed nations. Blood use has declined significantly in the past decade in the USA, between 2009 and 2016 the number of blood units collected and distributed by the American Red Cross decreased by $26 \%$ and predictions for $40 \%$ decrease by 2020, raises the issue of a crisis in the US blood system [124]. Blood is an essential medicine with no replacement likely in the foreseeable future and safer blood supply is paramount for public health planning.

Prevention of multiple infectious agents being transmitted by blood transfusion is very expensive, time consuming and cumbersome. Many of the blood donation screening measures exceed US \$1 million per quality-adjusted life-year gained, which are 10 times as high as deemed appropriate in clinical medicine [125]. The key to a safe and affordable blood system is a universally applied pathogen-reduction system that can inactivate all or most viruses, parasites, bacteria, and prions that can be implemented by resource-poor and resource-rich countries alike. This would obviate the need for expensive screening by serology, NAT, and others. Several methods of pathogen reduction are already in use including Mirasol [TerumoBCT, Lakewood, Co, USA] using a combination of riboflavin and UVB light can be applied to RBC and platelets to reduce most TT-viruses including HIV, HCV, and HBV by 2.3-5.19 log reduction as well parasites and bacteria; INTERCEPT [Cerus Corporation, Concord, CA, USA] utilize amotosalen and UVA light has shown similar properties against viruses, bacteria, and parasites; THERAFLEX [MacoPharma, Lille, France] uses photochemical inactivation with different methods for plasma and platelets, has demonstrated efficacy against viruses and bacteria, but 2 cases of HIV transmission have occurred after treatment of plasma; solvents/ detergents for treatment of plasma is very effective against a wide array of enveloped and intracellular viruses, bacteria, and protozoa and can be combined with filtration to improve efficacy; chemical alkylating agents are also under investigation [126]. Larger comparative trials are needed to find the most suitable technique that can be used for whole blood, RBC, platelets, and plasma, to prevent transfusiontransmitted infection in the future. 


\section{References}

1. Stramer SL, Hollinger FB, Katz LM et al (2009) Emerging infectious disease agents and their potential threat to transfusion safety. Transfusion 49:1S-29S

2. Stramer SL, Dodd RY, AABB Transfusion-Transmitted Disease Emerging Infectious diseases Subgroup (2013) Transfusion-transmitted emerging disease infectious diseases: 30 years of challenges and progress. Transfusion 53:2375-2383

3. Jones KE, Levy MA et al (2008) Global trends in emerging infectious diseases. Nature 451:990-994

4. Cardo LJ (2008) Leishmania: risk to the blood supply. Transfusion 48:1333-1341

5. Hladik W, Dollard SC, Mermin J et al (2006) Transmission of human herpesvirus-8 by blood transfusion. N Engl J Med 355:1331-1338

6. Dollard SC, Nelson KE, Ness PM, Stambolis V, Kuehnert MJ, Pellett PE, Cannon MJ (2005) Possible transmission of human herpesvirus- 8 by blood transfusion in a historical United States cohort. Transfusion 45:500-503

7. Matsubayashi K, Kang JH, Sakata $\mathrm{H}$ et al (2008) A case of transfusion transmitted hepatitis E caused by blood from donor infected with hepatitis $\mathrm{E}$ virus via zoonotic food-borne route. Transfusion 48:1368-1375

8. Boxall E, Herborn A, Kochethu G, Pratt G, Adams D, Ijas S, Teo C-G (2006) Transfusiontransmitted hepatitis E in a "non-hyperendemic" country. Transfus Med 16:79-83

9. Stramer SL (2014) Current perspectives in transfusion-transmitted infectious diseases: emerging and re-emerging infections. ISBT Sci Ser 9:30-36

10. Xu T, Yi ZM, Luo JM et al (2018) Prevalence and trends of transfusion-transmittable infection among blood donors in Southwest China. J Public Health 17:17

11. Li L, Li KY, Yan K et al (2017) The history and challenges of blood donors screening in China. Transfus Med Rev 31:89-93

12. He M, Wang J, Chen L, Liu J, Zeng P (2017) The impact of emerging infectious diseases on Chinese blood safety. Trans Med Rev 31:94-101

13. Wang W, Liao Q, Wu X et al (2015) Potential risk of blood transfusion-transmitted brucellosis in an endemic area of China. Transfusion 55:586-592

14. Nelson KE (2014) Transmission of hepatitis E virus by transfusion: what is the risk? Transfusion 54:8-10

15. Guo QS, Yan Q, Xiong JH et al (2010) Prevalence of hepatitis E virus in Chinese blood donors. J Clin Microbiol 48:317-318

16. Du J, Chen C, Gao J et al (2014) History and update of HTLV infection in China. Virus Res 55(191):134-137

17. Grogl M, Daugirda JL, Hoover DL, Magill AJ, Berman JD (1993) Survivability and infectivity of Leishmania tropica from operation desert storm participants in human blood products maintained under blood bank conditions. Am J Trop Med Hyg 49:308-315

18. Young NS, Brown KE (2004) Parvovirus B19. N Engl J Med 350:586-597

19. Hogema BM, Slot E, Molier M et al (2012) Coxiella burnetti infection among blood donors during the 2009 Q-fever outbreak in the Netherlands. Transfusion 52:144-150

20. Siraj N, Achila OO, Isaac J et al (2018) Seroprevalence of transfusion-transmittable infections among blood donors at the National Blood Transfusion Service, Eritrea: a seven-year retrospective study. BMC Infect Dis 18:264

21. Teklemariam Z, Mitiku H, Waldegebreal F (2018) Seroprevalence and trends of transfusion transmitted infections at Harar blood bank in Harari regional state, Eastern Ethiopia: eight years retrospective study. BMC Hematol 18:24

22. Mohammed Y, Bekele A (2016) Seroprevalence of transfusion transmitted infections among blood donors at Jijiga blood bank, Eastern Ethiopia: retrospective 4 year study. BMC Res Notes 9:129

23. Onyango CG, Ogonda L, Guyah B et al (2018) Seroprevalence and determinants of transfusion transmissible infections among voluntary blood donors in Homobay, Kisumu and Siaya counties in western Kenya. BMC Res Notes 11:410 
24. Okoroiwu HU, Okafor IM, Asemota EA, Okpokam DC (2018) Seroprevalence of transfusiontransmissible infections [HBV, HCV, syphilis and HIV] among prospective blood donors in a tertiary health care facility in Calabar, Nigeria: an eleven years evaluation. BMC Public Health 18:645

25. Tafesse TB, Gebru AA, Gobalee S et al (2017) Seroprevalence and diagnosis of HIV, HBV, HCV and syphilis infections among blood donors. Hum Antibodies 25:39-55

26. Brown BJ, Oladokun RE, Ogunbosi BO, Osinusi K (2017) Blood-transfusion-associated HIV infection in children in Ibadan, Nigeria. J Int Assoc Provid AIDS Care 16:303-308

27. Cable R, Leslie N, Bird A (2013) Reduction of the risk of transfusion-transmitted viral infections by nucleic acid amplification testing in Western Cape of South Africa: a 5 year review. Vox Sang 104:93-99

28. Fahashadpour F, Tajbakhani R, Tajbakhsh S et al (2016) Prevalence and trends of transfusion transmissible viral infections among blood donors in south of Iran: an eleven-year retrospective study. PLoS One 11:e0157615

29. Souan L, Tout F, Siag M, Sughayer MA (2016) Seroprevalence rates of transfusiontransmitted infections among blood donors in Jordan. J Infect Dev Ctries 10:377-383

30. Nada HA, Atwa M (2013) Seroprevalence of HBV, HCV, HIV and syphilis markers among blood donors at Suez Canal University Hospital Blood Bank. J Blood Disorders Transfus 5:177

31. Saeed M, Hussain S, Rasheed F, Ahmad M, Arif M, Hamid Rahmani MT (2017) Silent killers: transfusion transmissible infections-TTI, among asymptomatic population of Pakistan. JPMA J Pak Med Assoc 67:369-374

32. Karmaker PR, Shrivastava P, Ray TG (2014) Seroprevalence of transfusion transmissible infections in blood donors at the blood bank of a Medical College of Kolkata. Indian J Public Health 58:61-64

33. Mandal R, Mondal K (2016) Transfusion transmissible infections among blood donors from sub-Himalayan rural tertiary care center in Darjeeling, India. J Tradit Complement Med 6:224-229

34. Chandra T, Rizvi SN, Agarwal D (2014) Decreasing prevalence of transfusion transmitted infections in Indian scenario. Sci World J 2014:173939

35. Chiamchanya N (2014) The prevalence of transfusion-transmissible infection in blood donors in Thammasat University hospital between 2007-2012. J Med Assoc Thail 97:1055-1063

36. Veira PCM, Lamarao LM, Amaral CEM et al (2017) Residual risk of transmission of human immunodeficiency virus and hepatitis $\mathrm{C}$ virus infections by blood donation in northern Brazil. Transfusion 57:1968-1975

37. Blanco S, Balangero MC, Valle MC, Montini OL, Carrizo LH, Gallego SV (2017) Usefulness of nucleic acid testing to reduce risk of hepatitis B virus transfusion-transmitted infection in Argentina: high rate of recent infections. Transfusion 57:816-822

38. Gomez LA, Penuela O, Higuera F (2014) Prevalence of antibodies against transfusiontransmissible infections [TTI] in blood donors from the Colombian eastern region. Clin Lab 60:869-871

39. Dodd RY, Notari EP, Nelson D et al (2016) Development of a multisystem surveillance database for transfusion-transmitted infections among blood donors in the United States. Transfusion 56:2781-2789

40. Slot E, Janssen MP, van der Kreek TM, Zaaijer HL, van de Laar TJ (2016) Two decades of risk factors and transfusion-transmissible infections in the Dutch blood donors. Transfusion 56:203-214

41. Rehambiah LK, Rehambiah LE, Bengone C, Djoba Siawaya JF (2014) The risk of transfusion transmitted viral infections at the Gaboese National Blood Transfusion Centre. Blood Transfus 12:330-333

42. Viera PCM, Lamrao LM, Amaral CEM et al (2017) Residual risk of transmission of human immunodeficiency virus and hepatitis $\mathrm{C}$ virus infections by blood transfusion in northern Brazil. Transfusion 57:1968-1976 
43. Garraud O, Filho LA, Laperche S, Tayou-Tagny C, Pozzetto B (2016) The infectious risk in blood transfusion as of today - a no black and white situation. Presse Med 45:e303-e311

44. Ainley LI, Hewitt PE (2018) Haematology patients and the risk of transfusion transmitted infections. Br J Haematol 180:472-483

45. Ziemann M, Thiele T (2017) Transfusion-transmitted CMV infection—current knowledge and future perspectives. Transfus Med 27:238-248

46. Mainou M, Alahdab F, Tobian AA et al (2016) Reducing the risk of transfusion-transmitted cytomegalovirus infection: a systemic review and meta-analysis. Transfusion 56:1569-1580

47. Candotti D, Boizeau L, Laperche S (2017) Occult hepatitis B infection and transfusiontransmission risk. Transfus Clin Biol 24:189-195

48. Taira R, Satake M, Momose $S$ et al (2013) Residual risk of transfusion-transmitted hepatitis $B$ virus [HBV] infection caused by blood components derived from donors with occult HBV infection in Japan. Transfusion 53:1393-1404

49. Seed CR, Kiely P (2013) A method of estimating the residual risk of transfusion-transmitted $\mathrm{HBV}$ infection associated with occult hepatitis B virus infection in a population without universal anti-HBc screening. Vox Sang 105:290-298

50. Moresco MN, Virgolino Hde A, de Morais MP et al (2014) Occult hepatitis B virus infection among blood donors from the Brazilian Amazon: implications for transfusion policy. Vox Sang 107:19-25

51. Candotti D, Assennato SM, Laperche S, Allain JP, Levicnik-Stezinar S (2019) Multiple HBV transfusion transmission from undetected occult infections: revising the minimal infectious dose. Gut 68:313-321. https://doi.org/10.1136/gutjnl-2018-316490

52. Rein DB, Stevens GA, Theaker J, Wittenborn JS, Wiesma ST (2012) The global burden of hepatitis E virus genotypes 1 and 2 in 2005. Hepatology 55:988-997

53. Fong IW (2017) Hepatitis E: a zoonosis. In: Emerging zoonoses. A worldwide perspective. Springer, Cham, pp 155-171

54. Hogema BM, Mollier M, Sierps M et al (2016) Incidence and duration of hepatitis E virus infection in Dutch blood donors. Transfusion 56:722-728

55. Izopet J, Lhomme S, Chapuy-Regaud S, Mansuy JM, Kamar N, Abravanel F (2017) HEV and transfusion-recipient risk. Transfus Clin Biol 24:176-181

56. Khuroo MS, Kamili S, Yattoo GN (2004) Hepatitis E virus infection may be transmitted through blood transfusion in an endemic area. Gastroenterol Hepatol 19:778-784

57. Dreier J, Knabbe C, Vollmer T (2018) Transfusion-transmitted hepatitis E: NAT screening of blood donations and infectious dose. Front Med. https://www.frontiersin.org/articles/10.3389/ fmed.2018.00005/full

58. Hewitt PE, Ijaz S, Brailsford SR et al (2014) Hepatitis E virus in blood components: a prevalence and transmission study in southeast England. Lancet 384:1766-1773

59. Ankcorn MJ, Tedder RS (2017) Hepatitis E: the current state of play. Transfus Med 27:84-95

60. Fong IW (2017) Chikungunya virus and Zika virus expansion: an imitation of dengue virus. In: Emerging zoonoses. A worldwide perspective. Springer, Cham, pp 101-130

61. Centers for Disease Control (1975) Transmission of Colorado tick virus by blood transfusion-Montana. MMWR 24:422-427

62. Pealer LN, Marfin AA, Petersen LR et al (2003) Transmission of West Nile virus through blood transfusion in the United States in 2002. N Engl J Med 349:1236-1245

63. Biggerstaff BJ, Petersen LR (2003) Estimated risk of the West Nile virus through blood transfusion in the US, 2002. Transfusion 43:10007-10017

64. Busch H, Caglioti S, Robertson EF et al (2005) Screening the blood supply for West Nile virus RNA by nucleic acid amplification testing. N Engl J Med 353:460-467

65. Custer B, Busch MP, Marfin AA, Petersen LR (2005) The cost-effectiveness of screening US blood supply for West Nile virus. Ann Intern Med 143:486-492

66. Petersen LR, Busch MP (2010) Transfusion-transmitted arboviruses. Vox Sang 98:495-503

67. Levi JE (2016) Dengue virus and blood transfusion. J Infect Dis 213:689-690

68. Sabino EC, Loureiro P, Lopes ME et al (2016) Transfusion-transmitted dengue and associated clinical symptoms during the 2012 epidemic in Brazil. J Infect Dis 213:694-702 
69. Appassakij H, Promwong C, Rujirojindakul P, Khuntikij P, Silpapojakul K (2016) Risk of transfusion-transmitted chikungunya infection and efficacy of blood safety implementation measures: experience from the 2009 epidemic in Songkhla Province, Thailand. Transfusion 56:2100-2107

70. Lustig Y, Mendelson E, Paran N, Melamed S, Schwartz E (2016) Detection of Zika virus RNA in whole blood up to 2 months after symptoms onset, Israel, December 2015 to April 2016. Euro Surveill 21(26):30269

71. Barjas-Castro ML, Angerami RN, Cunha MS et al (2016) Probable transfusion transmitted Zika virus in Brazil. Transfusion 56:1684-1688

72. Motta IJ, Spencer BR, Cordeiro da Silva SG et al (2016) Evidence for transmission of Zika virus by platelet transfusion. N Engl J Med 375:1101-1103

73. Musso D, Nhan T, Robin E et al (2014) Potential for Zika virus transmission through blood transfusion demonstrated during an outbreak in French Polynesia, November 2013 to February 2014. Euro Surveill 19(14):20761

74. Kuehnert MJ, Basavaraju SV, Moseley RR et al (2016) Screening of blood donations for Zika virus infection-Puerto Rico, April 3-June 11 2016. MMWR Morb Mortal Wkly Rep 65:627-628

75. Gallian P, Cabie A, Richard P et al (2017) Zika virus in asymptomatic blood donors in Martinique. Blood 129:263-266

76. Cumulative Zika virus disease case counts in the United States, 2015-2018. Centers for disease Control and Prevention. https://www.cdc.gov/zika/reporting/case-counts.htm1

77. Saa P, Proctor M, Foster G et al (2018) Investigational testing for Zika virus among US blood donors. N Engl J Med 378:1778-1788

78. Ellingson KD, Sapiano MRP, Haass KA et al (2017) Cost projections for implementation of safety interventions to prevent transfusion-transmitted Zika virus infections in the United States. Transfusion 57(Suppl 2):1625-1633

79. Bloch EM, Ness PM, Tobian AAR, Sugarman J (2018) Revisiting blood safety practices given emerging data about Zika virus. N Engl J Med 379:1837-1841

80. Russell WA, Stramer SL, Busch MP, Custer B (2019) Screening the blood supply for Zika virus in the 50 US States and Puerto Rico. Ann Intern Med 170:164-174

81. Dunstan RA, Seed CR, Keller AJ (2008) Emerging viral threats to the Australian blood supply. Aust N Z J Public Health 32:354-360

82. Seed CR, Hoad VC, Faddy HM, Kiely P, Keller AJ, Pink J (2016) Re-evaluating the residual risk of transfusion-transmitted Ross River virus infection. Vox Sang 110:317-323

83. Anderson LJ, Tsou C, Parker RA et al (1986) Detection of antibodies and antigens of human parvovirus B19 by enzyme-linked immunosorbent assay. J Clin Microbiol 24:522-526

84. Heegaard ED, Brown KE (2002) Human parvovirus B19. Clin Microbiol Rev 15:485-505

85. Takahashi T, Ozawa K, Takahashi K et al (1990) Susceptibility of human erythropoeitic progenitor cells to B19 parvovirus in vitro increases with differentiation. Blood 75:603-610

86. Siegal G, Cassinotti P (1998) Presence and significance of parvovirus B19 in blood and blood products. Biologicals 26:89-94

87. Marano G, Vaglio S, Pupella S et al (2015) Human parvovirus B19 and blood product safety: a tale of twenty years of improvements. Blood Transfus 13:184-196

88. Norja P, Lassikla R, Makris M (2012) Parvovirus transmission by blood products-a cause for concern? Br J Haematol 159:385-393

89. Blumel J, Burger R, Drosten C et al (2010) Parvovirus B19-revisited. Transfus Med Hemother 37:339-350

90. Nagaharu K, Sugmoto Y, Hoshi Y et al (2017) Persistent symptomatic parvovirus B19 infection with severe thrombocytopenia transmitted by red blood cell transfusion containing low parvovirus B19 DNA levels. Transfusion 57:1414-1418

91. Gessain A, Cassar O (2012) Epidemiological aspects and world distribution of HTLV-1 infection. Front Microbiol 3:388

92. Szczypinska EM (2014) Human T-cell lymphotropic viruses. Medscape. http://emedicine. medscape.com/article/219285-overview 
93. Murphy EL (2016) Infection with human T-lymphotropic virus types-1 and -2 [HTLV-1 and -2]: implications for blood transfusion safety. Transfus Clin Biol 23:13-19

94. Gout O, Boulac M, Gessain A et al (1990) Rapid development of myelopathy after HTLV-1 infection acquired by transfusion during cardiac transplantation. N Engl J Med 322:383-388

95. Chen YC, Wang CH, Su IJ et al (1989) Infection of human T-cell leukemia virus type-1 and development of human T-cell leukemia lymphoma in patients with hematologic neoplasms: a possible linkage to blood transfusion. Blood 74:388-394

96. Stigum H, Magnus P, Samdal HH, Nord E (2000) Human T-cell lymphotropic virus testing of blood donors in Norway: a cost-effect model. Int J Epidemiol 29:1076-1084

97. Woolsey G (1911) Transfusion for pernicious anemia. Transgend NY Surg Soc, pp 132-133

98. Abdullah S, Karunamoorthi K (2016) Malaria and blood transfusion: major issues of blood safety in malaria-endemic countries and strategies for mitigating the risk of Plasmodium parasites. Parasit Res 115:35-47

99. Owusu-Ofori AK, Parry C, Bates I (2010) Transfusion-transmitted malaria in countries where malaria is endemic: a review of the literature from sub-Saharan Africa. Clin Infect Dis 51:1192-1198

100. Ali N, Ahmed J, Ali N, Jehan F, Saleem S (2010) Transfusion transmitted malaria in three major blood banks of Peshawar, Pakistan. Afri J Biotechnol 9:5445-5449

101. Bahadur S, Jain M, Pujani M (2010) Use of rapid detection tests to prevent transfusion transmitted malaria in India. Asian J Transfus Sci 4:140-141

102. Maselli LM, Levy D, Laporta GZ et al (2014) Detection of Plasmodium falciparum and Plasmodium vivax subclinical infection in non-endemic region: implications for blood transfusion and malaria epidemiology. Malar J 13:224

103. Verra F, Angheben A, Martello E, Giorli G, Prandin F, Bisoffi Z (2018) A systematic review of transfusion-transmitted malaria in non-endemic areas. Malar J 17:36

104. Allain JP, Owusu-ofori AK, Assennato SM, Marschner S, Goodrich RP, Owusu-Ofori S (2016) Effect of Plasmodium inactivation in whole blood on the incidence of blood transfusion-transmitted malaria in endemic regions: the African investigation of the Mirasol System [AIMS] randomized controlled trial. Lancet 387:1753-1761

105. Schmunis GA (1991) Trypanosoma cruzi, the etiologic agent of Chagas disease: status in the blood supply in endemic and nonendemic countries. Transfusion 31:547-557

106. Angheben A, Boix L, Buonfrate D et al (2015) Chagas disease and transfusion medicine: a perspective from non-endemic countries. Blood Transfus 13:540-550

107. Ries J, Korarek A, Gottshalk J et al (2016) A case of possible Chagas transmission by blood transfusion in Switzerland. Transfus Med Hemother 43:415-417

108. Cancino-Faure B, Fisa R, Riera C, Bula I, Girona-Llobera E, Jiminez-Marco T (2015) Evidence of meaningful levels of Trypanosoma cruzi in platelet concentrates from seropositive blood donors. Transfusion 55:1249. https://doi.org/10.1111/trf.12989

109. Herwaldt BL, Linden JV, Boserman E, Young C, Olkowska D, Wilson M (2011) Transfusionassociated babesiosis in the United States: a description of cases. Ann Intern Med 155:509-519

110. Fang DC, McCullough J (2016) Transfusion-transmitted Babesia microti. Transfus Med Rev 30:132-138

111. Linden JV, Prusinski MA, Crowder LA et al (2018) Transfusion-transmitted and communityacquired babesiosis in New York, 2004 to 2015. Transfusion 58:660-668

112. Burgess MJ, Rosenbaum ER, Pritt BS et al (2017) Possible transfusion-transmitted Babesia divergens-like/MO-1 infection in an Arkansas patient. Clin Infect Dis 64:1622-1625

113. Young C, Kraus PJ (2009) The problem of transfusion-transmitted babesiosis. Transfusion 49:2548-2550

114. Moritz ED, Winton CS, Tonnetti L et al (2016) Screening for Babesia microti in the US blood supply. N Engl J Med 375:2236-2245

115. Lannan KL, Sahler J, Spinelli SL, Phipps RP, Blumberg N (2013) Transfusion immunomodulation-the case for leucoreduced and [perhaps] washed transfusion. Blood Cells Mol Dis 50:61-68 
116. Rhode JM, Dimcheff DE, Blumberg N et al (2014) Health care-associated infection after red blood cell transfusion. A systematic review and meta-analysis. JAMA 311:1317-1326

117. Zia M (2017) Transfusion-transmitted diseases. Bacterial infections Medscape. Updated 15 Jan 2017. http://emedicine.medscape.com/article/1389957-overview\#a2

118. Kreuger AL, Middelburg RA, Kerkhoffs JH, Schipperus MR, Wiersum-Osselton JC, van der Bom JG (2017) Storage medium of platelet transfusions and the risk of transfusiontransmitted bacterial infections. Transfusion 57:657-660

119. US Food and Drug Administration (2013) Fatalities reported to FDA following blood collection and transfusion: annual summary for Fiscal year 2013. https://www.fda. gov/BiologicsBloodVaccines/safety/Availability/Report/transfusionDonationFatalities/ ucm391574.htm

120. Fatalities reported to FDA following blood collection and transfusion: annual summary for Fiscal Year 2015. http://transfusion.ru/2016/12-05-2.pdf2015

121. Hong H, Xiao W, Lazarus HM, Good CE, Maitta RW, Jacobs MR (2016) Detection of septic transfusion reactions to platelet transfusion by active and passive surveillance. Blood 127:496-502

122. Hume HA, Ddungu H, Angom R et al (2016) Platelet transfusion therapy in sub-Saharan Africa: bacterial contamination, recipient characteristics and acute transfusion reactions. Transfusion 56:1951-1959

123. Levy JH, Neal MD, Herman JH (2018) Bacterial contamination of platelet for transfusion: strategies for prevention. Crit Care 22:271

124. Klein HG, Hrouda JC, Epstein JS (2017) Crisis in the sustainability of the US blood system. N Engl J Med 377:1485-1488

125. Custer B, Hoch JS (2009) Cost-effectiveness analysis: what it really means for transfusion medicine decision making. Transfus Med Rev 23:1-12

126. Ware AD, Jacquot C, Tobian AAR, Gehrie EA, Ness PM, Bloch EM (2018) Pathogen reduction and blood transfusion safety and challenges of implementation in low-resource settings. Vox Sang 113:3-112

127. Di Minno G, Perno CF, Tiede A, Navarro D, Canaro M, Guertler L, Ironside JW (2016) Current concepts in the prevention of pathogen transmission via blood/plasma-derived products for bleeding disorders. Blood Rev 30:35-48

128. Rerambiah LK, Rerambiah LE, Bengone C, Djoba Siawaya JK (2014) The risk of transfusiontransmitted viral infections at the Gabonese National blood Transfusion Centre. Blood Transfus 12:330-333 